\title{
Examples to relate school mathematics to everyday life mediated by video, Tracker and GeoGebra
}

\author{
DOI: $10.46932 / \mathrm{sfjdv2n3-046}$
}

Received in: March $1^{\text {sh }}, 2022$

Accepted in: June $30^{\text {th }}, 2022$

\author{
Rafael Pantoja Rangel \\ Institution: University of Guadalajara, CUCEI, Department of Mathematics,Jalisco, Mexico \\ E-mail: profe.rpantoja@ hotmail.com \\ María Teresa Sánchez Vieyra \\ Institution: University of Guadalajara, CUCEI, Department of Mathematics,Jalisco, Mexico \\ E-mail: vieyra_84@hotmail.com \\ Maritza Elizabeth López Alcalá \\ Institution: University of Guadalajara, CUCEI, Department of Mathema \\ E-mail: elizabeth_box@ @otmail.com \\ Rafael Pantoja González \\ Technological Institute of Ciudad Guzmán, TNM, Jalisco, Mexico \\ Institution: University of Guadalajara, CUCEI, Department of Mathematics,Jalisco, Mexico \\ E-mail: rpantoja3@hotmail.com
}

\begin{abstract}
We describe video or photographic examples of everyday life problem situations that were analyzed using Tracker and GeoGebra. These examples were used in workshops taught in the classroom, at academic events and as part of a Calculus course in three institutions for engineering students. Further, the examples were used both for individual and collaborative work to learn the mathematics topics selected. Activities begin with obtaining records of semiotic representation, the data table, graphs, and the analytical expression, which relationship is established in order to generate the modeling of the problem situation. Based on classroom observation, the didactic sequence, the clinical interview, the written report and the presentation that was prepared and given, we claim that students learned the corresponding mathematics subject and that values such as punctuality, participation, honesty, interest and respect were encouraged to emerge throughout the process.
\end{abstract}

Keywords: semiotic representations, photography, video, problem situation, tracker, geogebra.

\section{INTRODUCTION}

Examples of everyday life problem situations are described in the article (Hitt, 2009, p. 6). These examples were used in workshops taught to engineering students coursing through the first two semesters at three institutions and at two academic events. The purpose of the workshops was to relate school mathematics with the contexts of everyday life in order to answer the common student question: Why do I have to learn this? To which the teacher often responds: You will see, you are going to need it. So gratification is always delayed and I think, says Pollak, that one cannot encourage motivation through the beauty of mathematics alone, without seeing its usefulness (Pollak, 2007, p. 111). To this question the teacher does not offer the student a satisfactory answer, because teaching 
mathematics in the classroom is geared towards algorithmic processes unrelated to applications in the context of the student, given that in academic life applications of school mathematics are postponed until specialization, a situation that justifies the argument that it will be dealt with at a later time.

In the case of mathematics courses, the question about knowledge received in class is recurring. Why do I have to learn this? or Where is it applied? The situation is largely motivated by the absence of a relationship between school mathematics and everyday life, since problem situations to which such knowledge is applicable have been, whether by personal preference or otherwise, simply eliminated. For example, to calculate the volume of the vessel in Figure 1 (a) students managed to fit the periphery to two polynomials, trajectories ABC and CD in Figure 1 (b), they found the integration limits, and used GeoGebra integration routines to approximate the volume of the solid using formula $V=\int_{a}^{b} \pi(f(x))^{2} d x$, the result of which did not coincide with the volume measured by filling it with water manually, by about 850 milliliters. And this caused confusion. This example patently shows that school mathematics differs from reality, because after a series of questions from the teacher, the container was even sketched without taking thickness into account on the board as if it could be then filled with liquid. Ultimately they realized that it is necessary to calculate the volume of the wall for the results to match. A tiny but necessary detai!

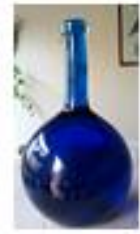

(a)
Figure 1. Volume of a vase.

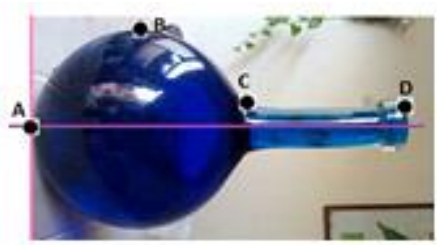

(b)

As Ezquerra (2011) points out, if an investigation of all the actions present in daily life is carried out and related to mathematics, one could save a lot of energy and do everything more effectively. This is because the proposals in which the student directly participates are an ideal framework to show how science is present in daily life, a fact that encourages the interest of students and their motivation to learn mathematics.

Hence the importance of taking up what Freudenthal raised (1980, p. 20) about including modeling in school mathematics, since there is value in integrating problem situations from the every day life of the actors (Pantoja, Nesterova \& Ulloa, 2013; Arrieta and Díaz, 2015; Pantoja, Guerrero and Ulloa 2016; Pantoja, Ortega \& Nesterova, 2017; Pantoja, 2020), as it is considered a good strategy for promoting student-student, student-teacher and pupil-TIC interactions, as well as certain values such as participation, respect, honesty and punctuality, among others.

The didactic interventions were implemented as options to promote learning the various mathematics topics selected, mediated by development of mathematical activities related to treatments and conversions (Duval, 2004), with the various semiotic representations generated from photographs, digital video of the objects and Tracker and GeoGebra. 
One of the factors that is added to the individual and collaborative work included in ACODESA, is the motivation of the students for this type of teaching strategies, since values such as punctuality, respect, participation and honesty are promoted, among others, in addition to promoting the qualities of attention, listening and dialogue, to promote a climate of optimal interpersonal relationships, in order to improve the participatory and supportive attitude in the development of activities (Bernárdez, Álvarez, Belmonte, 2021), because it was of interest to the project, relate school mathematics with daily life, as happened once the didactic intervention was applied.

\section{THEORY OF SEMIOTIC REPRESENTATIONS OF DUVAL (TRS): EXAMPLE OF THE WATER SPOUT}

The theory chosen, in view of its characteristics that support the examples, is the Theory of Semiotic Representations (Duval, 2004), which is described and interpreted with the example of the analysis of the parabolic (ideal) shape of a water spout captured via photography. In this case we start from the premise that when dealing with the subject of the parabola in the classroom, the coordinate axes are rarely moved. Hence the activities proposed for the water spout were planned so students can take advantage of the benefits of the Tracker software to move the coordinate plane with vertical and horizontal displacements and $90^{\circ}, 180^{\circ}$ and $270^{\circ}$ rotations, in order to identify the effect it has on the coefficients of the quadratic equation associated with the parabolic shape of the water spout. For example, we ask the question: Where would you place the coordinate plane (on the photograph) so that the independent term of the quadratic equation $y=a x^{2}+b x+c$ is equal to zero?

The workshop involved three phases with UAN engineering students and different photographs of a water spout were used in different positions (Figure 2a):

- The first phase was geared towards use of the Tracker and GeoGebra programs, in order to obtain the various semiotic representations (Figure $2 b$ ) for the water spout;

- The second phase is geared towards displacing the coordinate system horizontally and vertically to different positions so that the coefficients of the fitted quadratic equation meet a certain condition. For example, you may be asked: Where would you place the coordinate axes so that the representative equation for the shape of the waterspout does not have a linear term? This activity starts from the assumption that in the classroom the Cartesian plane remains fixed, and the parabola moves through the progression of an exercise. While in the proposal, the jet remains fixed and the coordinate system moves.

- The activity carried out in the third phase consisted of rotating the coordinate axes $90^{\circ}, 180^{\circ}$ and $270^{\circ}$, in order to enable students to differentiate between the various positions of the parabola in the Cartesian plane and the equations $y=a x^{2}+b x+c x=a y^{2}+b y+c$, which represent the parabolas with main axes parallel to the coordinate axes (Figure $2 b$ ). 
Figure 2. Photograph of the waterspout and its representation on Tracker.

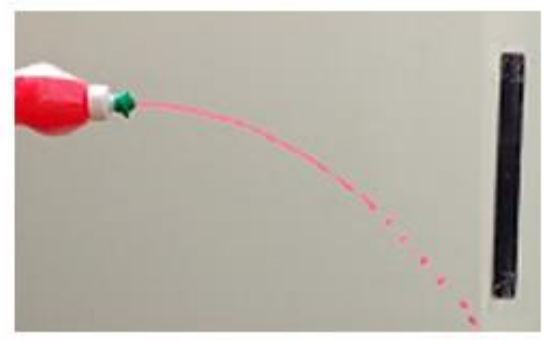

a

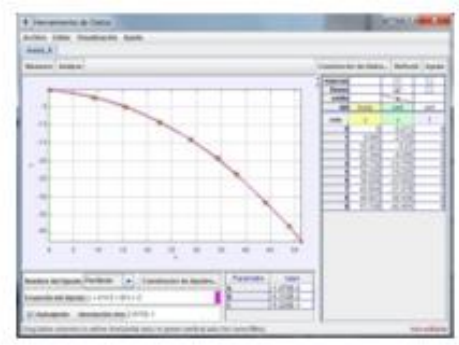

b

Figure 3 shows the relationship between the semiotic representations obtained for the waterspout. The semiotic representation records generated are:

- Visual: Photograph of the waterspout.

- Numerical: Trajectory data table.

- Graph: Trajectory of the waterspout.

- Analytical: Expression of the quadratic equation.

- Verbal: Discussion during the experimental phase and at the end when presenting the results.

- Written: Written responses in the workbook and in the delivery of the report of the activities carried out.

Figure 3. Records of semiotic representation records for waterspout

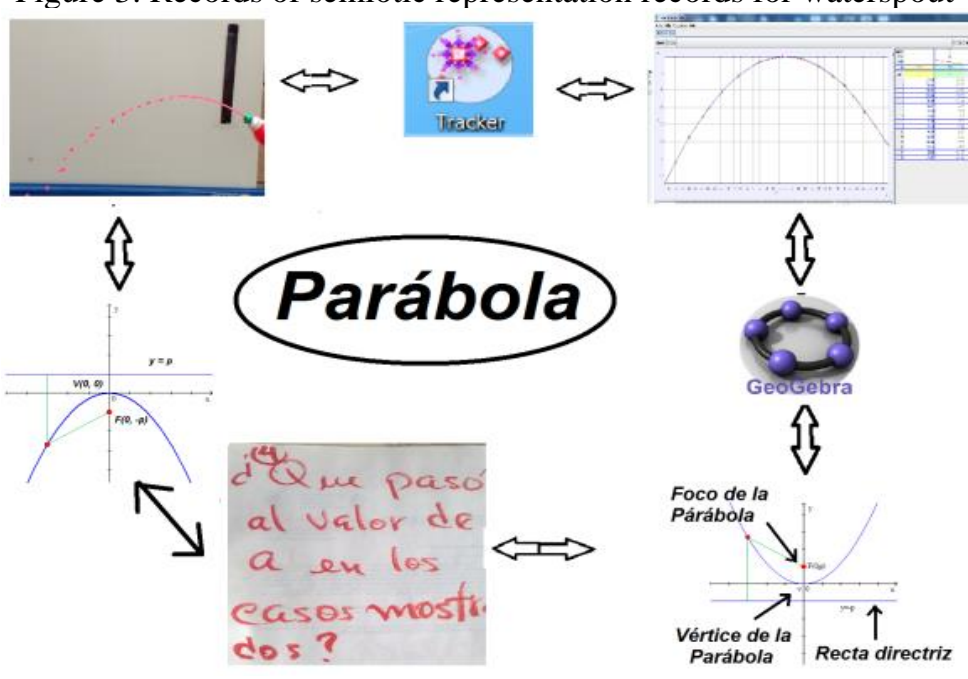

Once students working individually or collaboratively obtained representation records, they related them to mathematical work through treatments and conversions.

The conversions that were identified during the staging are:

- Graphic-Analytical. Determining the equation for the shape of the waterspout in the graph shown on the Tracker screen.

- Graphic-Numerical. Tracing the graphic shape on the computer screen to get the table of coordinates $(\mathrm{x}, \mathrm{y})$. 
- Analytical-Graphic. Describing the effect of quadratic coefficients through the coordinate plane displacements.

- Verbal-Written. Through group verbal discussions and preparing the report.

- Written-Verbal. Preparing the report and presenting to the group.

The treatments that were recognized are:

- Visual record. Relating the real sheet to the virtual sheet.

- Graphical record.

- Identifying the different shapes of the waterspout depending on the displacements and rotations.

- Translating or rotating the Cartesian plane.

- Written record. Completing the workbook and write a report.

- Verbal record. Discussion when carrying out the activities and presenting their results to the group.

The review of the reports of activities reflects the mathematical work developed by the students in the treatments and conversions, given that, from reviewing of the responses in the workbook, the videos showing the activities, the applied survey and the interview conducted, we conclude that the students managed to relate parameters a, b y c with vertical and horizontal displacements of the Cartesian plane, mediated by the analysis of the parabolic shape of a waterspout. They had difficulty when asked to rotate the coordinate axes $90^{\circ}, 180^{\circ}$ and $270^{\circ}$, which is normal, because these are activities that are not common in school mathematics (Pantoja, Ortega, Nesterova, 2017).

\section{ACODESA}

The individual and collaborative learning environment, debate, self-reflection and institutionalization (Hitt and Cortés, 2009; Hitt and González, 2015) are the phases comprised in the ACODESA methodology. In the first 3 phases the teacher is a guide and these are the moments when students argue and validate their productions, which they later link with the problem situation and finally the institutionalization process is the phase when teachers and students arrive at the institutional representations of the problem situation by mathematical modelling.

The ACODESA methodology is reflected from the time the design and manipulation of the recording set begins, because it involves the direct participation of students, as actors, videographers or photographers in obtaining video and photography. In this phase we note that students and teachers participating in the course lack prior knowledge of how to handle the devices so as to ensure quality video or photo, but the progress of CIT allows for this situation to be avoided because electronic equipment is self-programmable. Thus users are not preoccupied with this situation and instead can direct their efforts towards encouraging the linkage of school mathematics with the phenomenon. Let us not forget that the various didactic proposals were put forth so that the student would learn the selected mathematics topic.

With the use of video and photography, the following mathematics topics have been reviewed: polynomial adjustment, derivative as a rate of change, the solids of revolution method, parabola and second degree equation, 
areas of planar figures, parametric equations, linear functions and arc length (Pantoja, Sánchez \& Ortega, 2017, Pantoja, Valdivia, Guerrero \& Ulloa, 2018; Pantoja, Leal \& Villapando, 2016; Pantoja, Leal, 2017; Pantoja, R., Leal, Pantoja, D. A, 2017; Pantoja, R., Ferreyra \& Pantoja, G., R., 2019). The recording set has been designed for these topics and a large number of videos and photographs have been produced, from which the most suitable ones were selected to be processed with Tracker in order to obtain semiotic representation records. Figure 4 shows four corresponding recording sets: (a) filling containers; (b) motion of the train; (c) circular motion of a toy horse; (d) the runner.

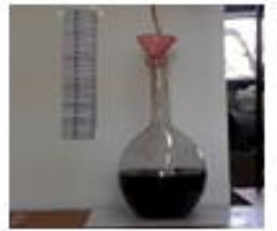

(a)
Figure 4. Examples of recording set for problem situations

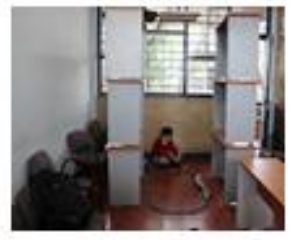

(b)

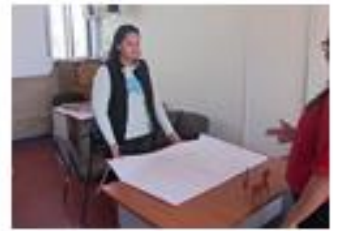

(c)

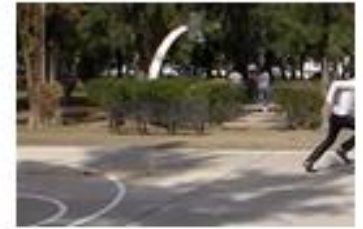

(d)

From the design of the recording set, the actions are developed in individual and collaborative work, answering the didactic sequences prepared using the formats proposed by Tobón (2010) and Díaz Barriga (2013), and that comprise theory, applications and questionnaires on the selected topic in relation to the problem situation. The final activity consists of delivering the didactic sequence, a report on their development and a group PowerPoint presentation to the whole group, which corresponds to written and verbal representation records because it is important for research to promote the student skills and abilities needed to prepare reports and present them to colleagues.

\section{TRACKER PRACTICE INVOLVING THE MOTION OF A RUNNER.}

Tracker is a free computer program for video analysis and model building developed in a Java environment. It is used for analysis of phenomena in motion, but it is also capable of approximating the surface area of flat shapes. The program is downloaded from the website http://www.cabrillo.edu/ dbrown/tracker/ and has been used in several problem situations. In this section it will be used to explain the methodology used to analyze three specific moments in the video of a runner moving along a straight line:

- Starting from rest, speed increases until the finish line is reached.

- Starting from rest, reach the finish line and return to the starting point.

- The runner enter into the scene at a constant speed, which is maintained until reaching the finish line.

The length of the track and staging time are dependent on the recording equipment and the route taken by the runner on a basketball court, where a two-meter ruler was placed as a visible reference in the video. The latter 
serves as the interface between real world measurement units and Tracker's measurement routine. The steps to follow to achieve the semiotic representations for the runner are:

a. Open Tracker, and to produce a video there are two options: a) select FileOpen and b) VideoImport.

b. Once the video is located on the screen, we move to manipulating the time slider placed at the bottom to delimit the segment of the video with which the path that is of interest to the user is identified. For example, if the recording consists of 463 frames, the controls are manipulated to select a video segment, for instance, 200 frames. Using the Cut Settings option (Right click on the video), the user selects how many frames will correspond to a point, thus, Start Frame $=$ 0, Step Size $=20$, End Frame = 199, means that the points are marked every 20 frames (the video advances automatically) from frame 0 all the way to the end of the table.

c. In the video recording set for the problem situation, a graduated ruler (or some equivalent) that is identifiable (visible) is included, whose function is to interface between the units of measurement of the actual object and the computer. The Calibration Rod is the Tracker's unit of measure and must be paired to the graduated ruler that was included in the video following the activation instructions, which are: Path $\rightarrow$ New $\rightarrow$ Calibration Tools $\rightarrow$ Calibration Rod or from the $\stackrel{+10}{+} \rightarrow$ New $\rightarrow$ Calibration Rod icon. Clicking on the calibration rod adds the measurement (in $\mathrm{cm}$ or meters) of the graduated ruler such that Tracker interprets the real measurements of the problem situation, in this case, $200 \mathrm{~cm}$.

d. The location of the Cartesian plane is left to the discretion of the user, who chooses where to place the coordinate axes. The axes can be moved and conveniently rotated, and it was centered it about the runner's waist because this is one of the places that is almost always constant on the surface. This was done in the interest of simplifying the graphical and analytical approach to the motion of the object.

e. The moving object in the problem situation is the runner, which is recognized as a Point Mass in Tracker. The instructions to activate it are: Trajectories $\rightarrow$ New $\rightarrow$ Point Mass.

f. Next we mark the path of motion, by first pressing the Shift+Click key combination as many times as selected under the option in subparagraph $b$. As the points are marked, the video automatically advances to the next position ( 20 frames ahead). At the same time, the point is marked in the coordinate system and its coordinate values are recorded in the appended table. Figure 5 shows the runner, the graph representing the horizontal distance traveled by the body with respect to time and the data table.

Figure 5. Recording set for the runner, the graph and the data
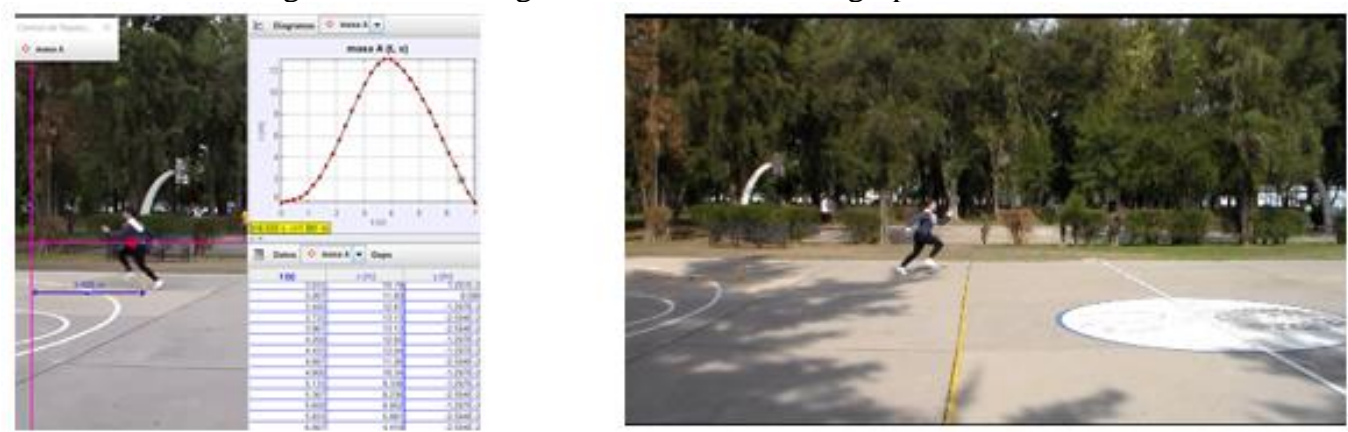
The analysis of the path of a runner is based on the answers given by students on the worksheet, which is made up of exercises and questions. A multiple choice survey that was assessed using the Likert scale was applied to the students on their experience in the workshop. In addition, each session was captured on video to analyze what was happening during the staging of each trial.

The research was qualitative, so the aspects considered related to the learning process of the students when carrying out the activities and to their motivation when working with situations related to their context. The experimental phase consisted of two working sessions: the first was instruction-based on the use of the Tracker and GeoGebra programs (Figure 6) for video analysis of the runner. For the second session, students were separated into groups and they were provided with the material composed of the worksheets and a video of a moving object to be used for analysis. After the practice, students were asked to go up to the board to present their ideas concerning what they learned.

When analyzing the results obtained in the experimentation phase, we observed that the students managed to describe, in writing in the worksheets and verbally in the question session, the derivative object from various perspectives: as the slope of a tangent line at a point on the graph of a function, as the limit of an incremental quotient and as instantaneous speed.

Figure 6. Graph and Modeling Data on the Motion of a Runner using GeoGebra.

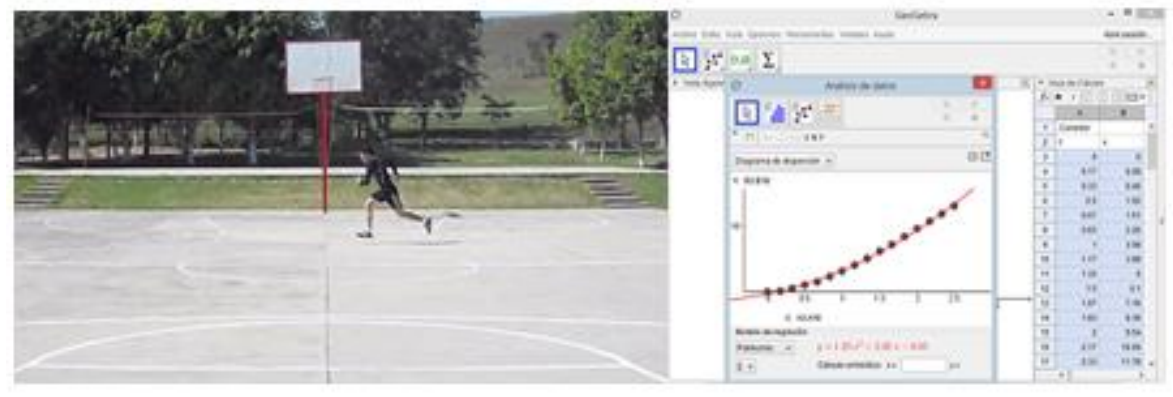

We conclude that use of modeling on everyday life situations facilitates student understanding of the derivative mathematical object. They identified the variables involved in the phenomenon; manage to obtain the analytical expression and to link data and graphs to the motion of the object.

\section{CALCULATING AREAS OF FLATTENED TREE LEAVES}

In Hitt (2015) the suggestion is to use problem situations in the student context, where they can potentially visualize the application of the Fundamental Theorem of Calculus (FTC) to approximate areas of varied sections of everyday objects. In this case: cross sections of fruits (avocado, apple, melon, carambola, mamey), entire flattened tree leaves and shapes and figures cut out of FOMI material (Figure 7), whose outlines resemble the various graphs of functions seen in the classroom. 
Figure 7. Areas of Flat Objects and the Fundamental Theorem of Calculus.
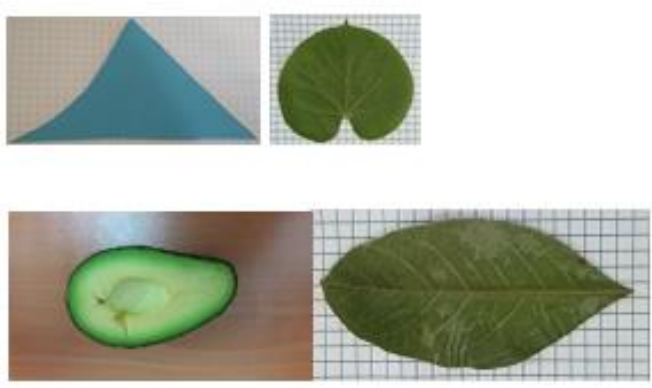

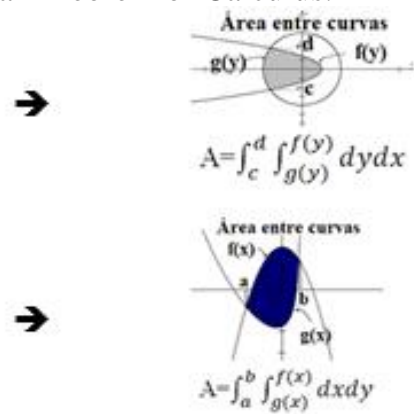

Tracker is designed to work with moving object video, and photography is an option that is considered when the object is fixed, as in the case of the contour that delimits the area of a complete or segmented tree leaf (Pantoja, Sánchez, 2017). In the latter, where the student is required to choose where to place the origin of the coordinate axis to delineate the regions of integration, to determine the functions and limits of integration and apply the FTC. The discussion focused on marking the set of points on the outline of the leaf, fitting each of curve segments to piece-wise continuous functions, as per their previous knowledge of functions (Figure 8). Some parts of the outline of the leaf that were assigned did not correspond to the definition seen in class and that generated one of the richest discussions in the classroom.

Figure 8. Flattened Tree Leaves
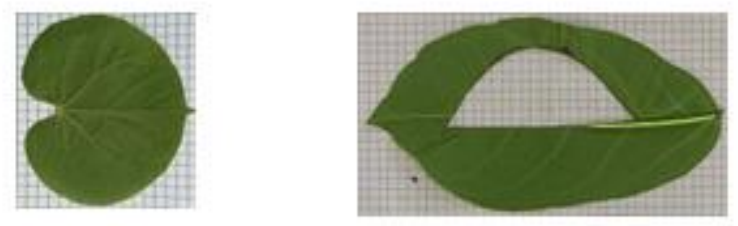

To identify the functions to the object area with Tracker, the user sketches the number of points to mark on the outline, which is identified with the total number of frames in the video included in the Cut Adjustment option, where the user modifies the parameters Start Box $=0$, Step Size $=1$, Final Box $=27$, which means that 27 points are marked (Figure 9a). Once the points on the tree leaf have been marked, the process begins of identifying the piece-wise continuous functions that make up the boundary and that correspond to the irregularity of the perimeter. For instance, in Figure 10b there are five functions that the student identified:

- Function 1: Points from A to B; Function 2: Points B to C; Function 3: Points C to D; Function 4:

Points from D to E; Function 5: Points from $\mathrm{F}$ to $\mathrm{E}$. 
Figure 9. Cut Setting Routine to process a photograph in Tracker.

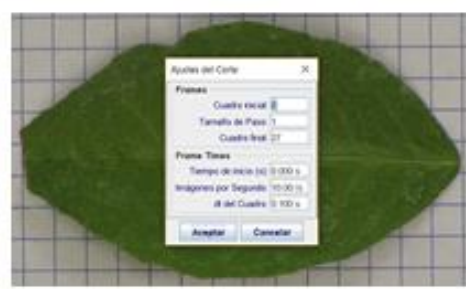

$\underline{\mathrm{a}}$

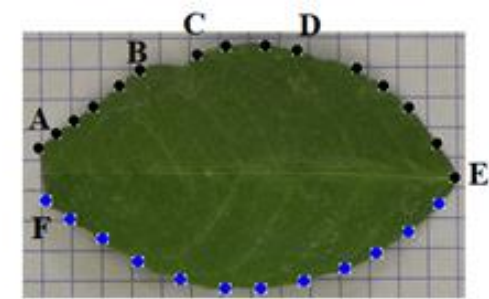

$\underline{b}$

Tracker has a limited routine for fitting functions, which is why the GeoGebra program is used. It has a variety of functions: linear, logarithmic, polynomial (up to grade 9), power, exponential, growth, sinusoidal and logistics.

The data table generated in Tracker is exported to GeoGebra, to determine the functions that model the periphery and apply the FTC to approximate the magnitude of the surface. The semiotic representation records that emerge under Duval's Theory are shown in Figure 10, which students related to treatments and conversions in order to obtain a mathematical model.

Figure 10. Semiotic representation of a flattened and segmented tree leaf.

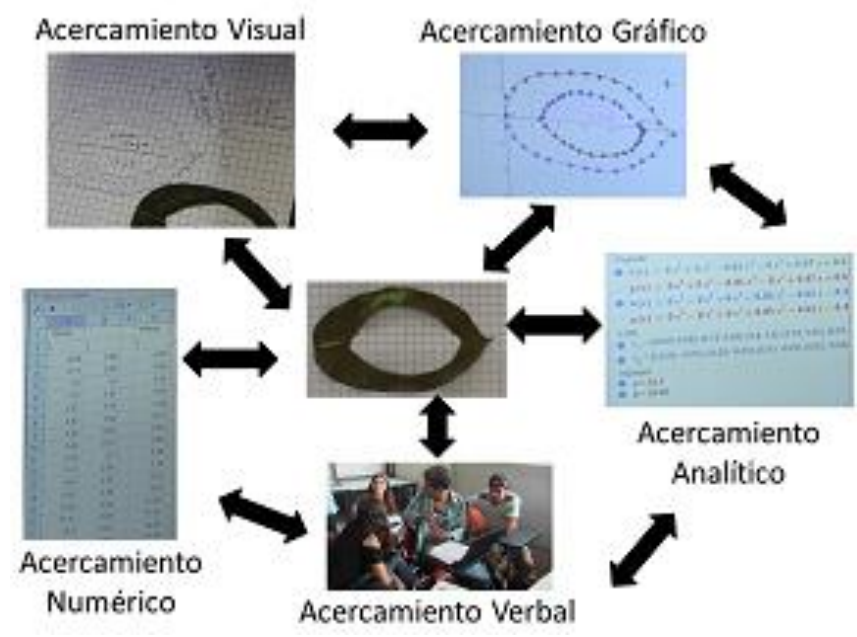

Figure 11a shows the tree leaf on grid paper, in order for the student to draw the outlines and determine two values that are close to the area with one being larger and one being smaller. Figure 11b shows the leaf in Tracker and Figure 11c shows the modeling on the computer in GeoGebra and the application of the FTC to approximate the area.

Figure 11. Modeling the area of the segmented tree leaf.

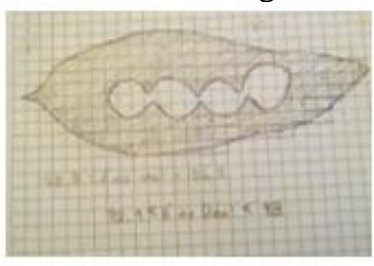

a

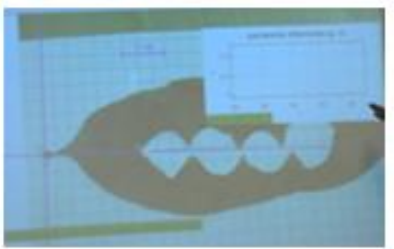

b

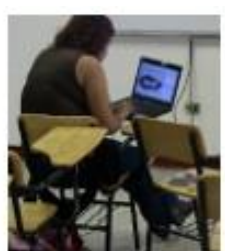


6 CALCULATION OF THE VOLUME OF A WATERMELON BY THE METHOD OF SOLIDS OF A REVOLUTION

This example refers to the approximation of the calculation of the volume of a watermelon by the method of solids of a revolution. The calculation of the volume was approached in four ways: first it was weighed on a scale (Figure 12a); then it was immersed in water and the displaced liquid was measured (Figure 12b); for the third step, the axes of the ellipsoid that resemble a watermelon were approximated using straight sticks and the formula was applied $V=\frac{4}{3} \pi a b c$ (Figure 12c);

Figure 12. Watermelon and its Modeling using GeoGebra

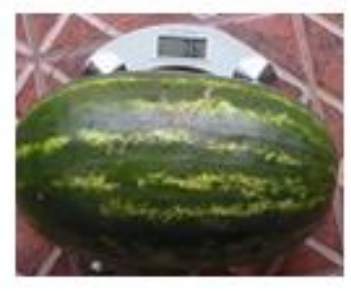

a

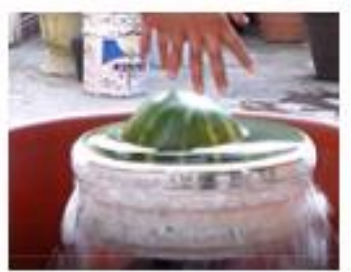

b

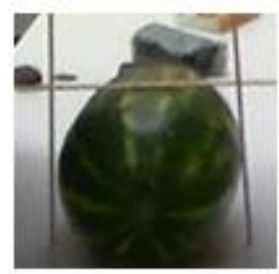

$\mathrm{C}$

Lastly, photography was used as a basis to promote the building of meaning for the mathematical objects of Integral Calculus using the Tracker and GeoGebra software. GeoGebra was used to model the outline. The volume was calculated as the solid of a revolution; and the object was simulated assuming symmetry in the watermelon (Figure 13).

Figure 13. Modeling and simulating the upper portion of watermelon
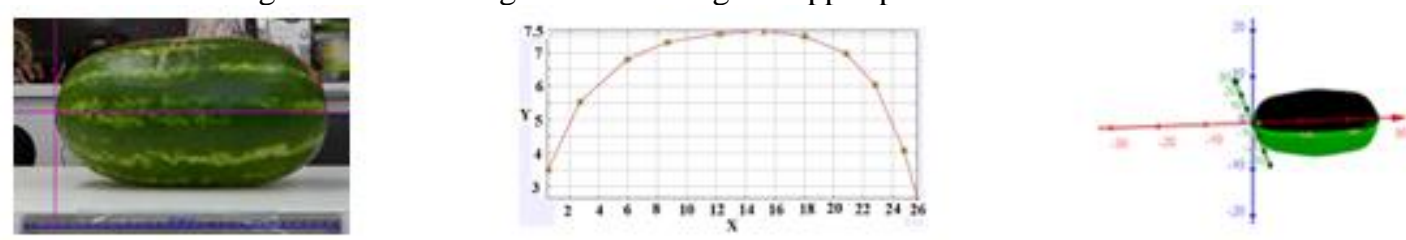

$g(x)=-0.00017 x^{4}+0.00838 x^{3}-0.156 x^{2}+1.34603 x+2.83847$.

At the end of the activities, a survey was applied to the 22 students. It was quantified using a Likert scale, which after analysis suggested that there is interest and motivation in this form of learning. The evidence collected during the experimental phase was obtained using a video camera, with which the individual and collaborative work was recorded in the classroom. In addition, with the analysis of surveys and reports we claim that the student managed to relate the concept of solid of a revolution to its context. We note that the methodology was applied to various everyday life objects such as glasses, a soccer ball, a melon and vases, among others. 


\section{THROWING A BALL INTO A HOOP IN A BASKETBALL GAME}

The study was developed in the course on Numerical Analysis in section D31 of the CUCEI, and 38 students participated. The activities were developed to promote the building of competence related to the mathematical modeling of a basketball shot (Figure 14): description of variables, graphs and determining the equation of the parabola associated with its motion.
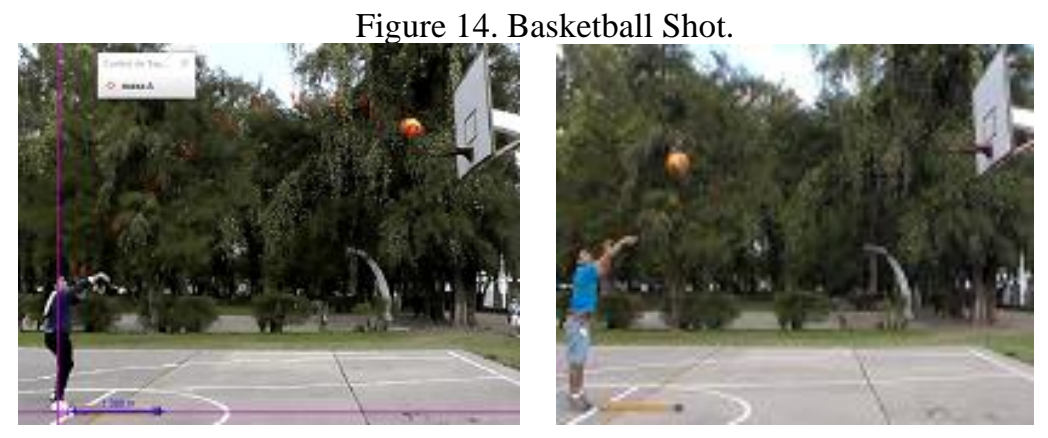

The discussion focused on the three graphs (Figure 15) obtained with Tracker for the trajectory of the object, as some confusion was observed from the fact that two second-degree equations and one first-degree equations arise in the description of motion, mainly because use of this type of activities (such as locating the coordinate axes and determining the intervening variables) is not proposed in the classroom. Further, they fail to notice that each shot of the ball generates a set of equations in the planes $\boldsymbol{x} \boldsymbol{v}$ s.t, $\boldsymbol{y} \boldsymbol{v s}$. $\boldsymbol{t}$, as does each relocation of the origin of the coordinate axes. They also fail to identify time as a variable.

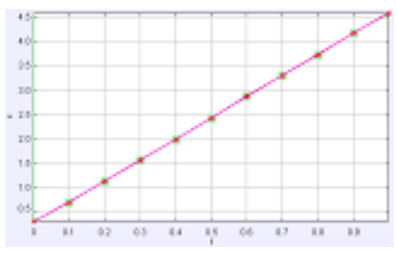

$x=.2765+4.328 t$

Figure 15. Graphs Associated with the Ball Shot.
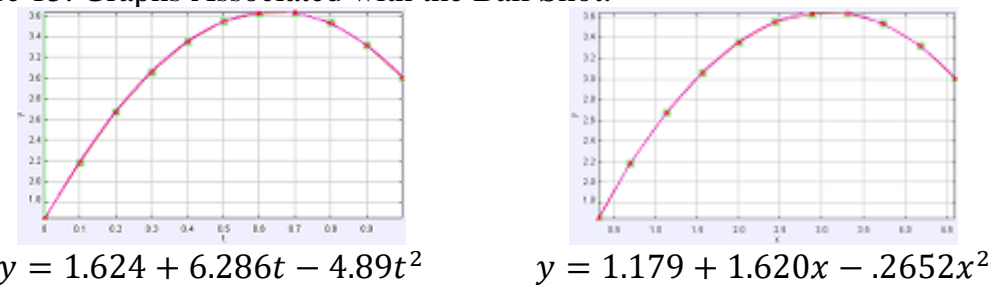

One of the most relevant discussions was on the analysis of the three graphs shown in Figure 15, each of which was meant to be explained as a function of the motion of the ball so as to identify the variables involved. This activity caused students to decompose the motion of the trajectory of the ball, similar to what Galileo (1633) did, first in relation to horizontal and uniform displacement (x versus $\mathrm{t}$ graph) and then in relation to vertical and uniformly accelerated displacement (y versus $\boldsymbol{t}$ graph) which is described as:

A projectile that slides with a movement composed of a horizontal and uniform motion and by a naturally accelerated downward motion describes, with that movement, a semi-parabolic line."

G. Galilei, Considerations and Demonstrations..., op. cit. (Theorem I, Proposition I) p. 129. 


\section{VOLLEYBALL GAME}

Two students started to play volleyball (Figure 16) and after analyzing the video to complete the task, they realized that for each shot an equation is generated. Hence to describe the game in a time interval, the representation of piece-wise continuous functions is used.

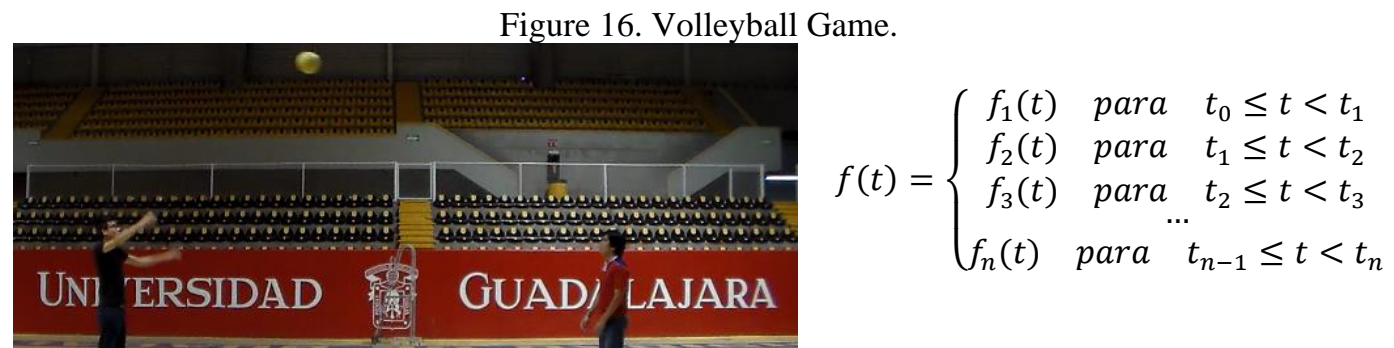

\section{THREE TRAJECTORIES FOR THE TOY TRAIN AND THE CONCEPT OF A PARAMETER}

This example uses the Motion of a Toy Train (Pantoja and López, 2019) that runs through the track set in three geometric shapes, namely: circular, elliptical and straight. The student designs the video recording set for the train journey (Figure 17) in order to obtain the coordinates of the points that mark the trajectory. This data is then exported to GeoGebra to fit the parametric equations from a dynamic perspective, since the point $\mathrm{P}(\mathrm{x}, \mathrm{y})$ on the moving train is displayed on the screen and it is shown in each of the three graphs shown on screen, as opposed to the static summary that is found in textbooks.

Figure 17. The Toy Train Track in a Circular Arrangement.
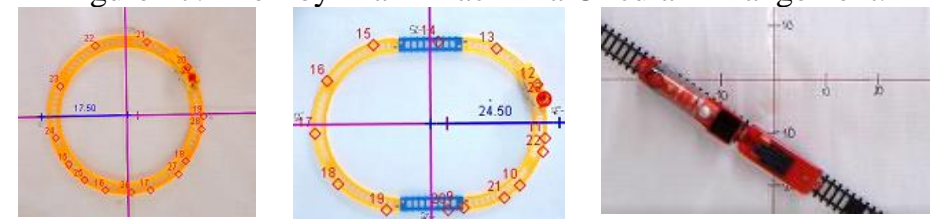

In the case of the circular track, the parametric equations identified are functions of the shape $x(t)=$ $A \cos (B t+C)$ and $y(t)=A \operatorname{sen}(B t+C)$. Their aim is for the student to relate to the movement of the train by analyzing the three graphical representations (Figure 18) provided in Tracker on planes $\boldsymbol{x} \boldsymbol{v s} . \boldsymbol{t}, \boldsymbol{y} \boldsymbol{v s . t} \boldsymbol{y} \boldsymbol{v s} \boldsymbol{x}$ and the interpretation of the constants $\mathrm{A}, \mathrm{B}$ and $\mathrm{C}$ on the train journey.

Figure 18. The Toy Train and its Graphical Representations.
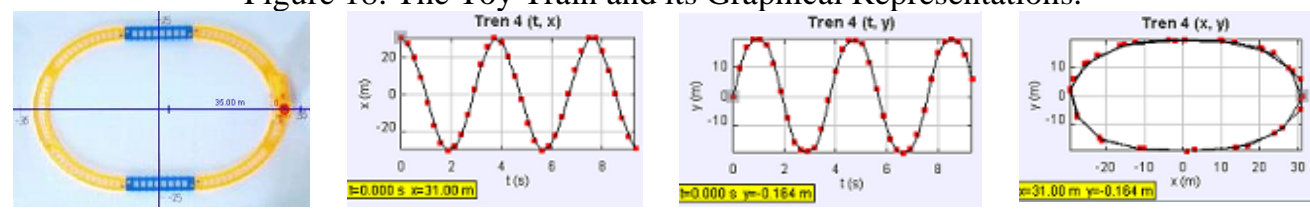

In the experimental phase, seven groups of four students and two groups of five students were put together. Each group was assigned two videos from a problem situation, and was given the Tracker and GeoGebra manuals 
as well as the worksheet. At the end of the activity each collaborative group was asked for a written report on development of the entire process and for a PowerPoint presentation. This reflected that students manage to shift between the records of verbal, pictorial, written, graphic, numerical and semiotic representations, with the mathematical activities proposed (Treatment and Conversion), actions that brought them to understand the concepts of parameter and parametric equations.

Figure 19 shows one of the students who worked with the videos of the toy train, but did not give the PowerPoint presentation due to lack of time. However, using a marker and blackboard they managed to present the situation that they had analyzed and the results, showing that they clearly possess the acquired knowledge because they correctly interpreted the study material.

Figure 19. Presentation of the Toy Train Case

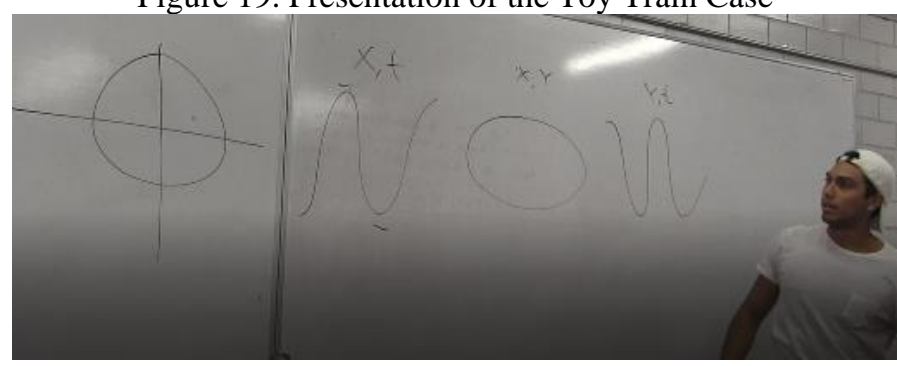

In general, with the analysis of the students' presentation we claim that they had no problem performing the analysis of the videos using CIT. We observed that they managed to interpret the results obtained, because they relate the different graphs to the trajectory of the object, its representations in parametric functions and the understanding of the concept of parameter. Moreover, something that is relevant to the study and interesting from the point of view of the UdeG educational model, is that the student performs individually and collaboratively (Figure 20), manages to relate mathematics with situations in his or her context and identifies variables, interprets graphs and analyzes numerical data.

Figure 20. Work on Binas with Tracker using the Photograph of the Train.
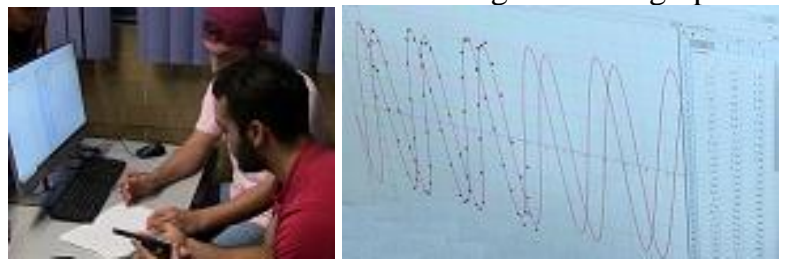

\section{THE STRUCTURE OF ELEVATED PEDESTRIAN BRIDGES: ARC LENGTH}

As with the examples presented in the article, there are various problem situations related to the concept of arc length. They can be included in the planning for the topic in the Calculus course, but for some circumstance they are omitted and rather taught in terms of the algorithmic process, as presented in the most used books on Calculus. Another aspect is that some of the application problems included in the texts are allegedly related to real life, but that is not the case. For example, problems 37 and 39 of the arc length chapter in the Steward Calculus 
book (2012, p 457) provides functions for problem situations, with the former giving the equation of a parabola $y=180-\frac{x^{2}}{45}$ that describes the trajectory of the prey released by a hawk, while the latter deals with function $y=$ $\operatorname{sen}\left(\frac{\pi x}{7}\right)$ that describes the shape of an ideal ribbed sheet. This differs from what is proposed in this section, where the photograph of the ribbed sheet is taken and the length of the sheet that was required to build it is determined (Figure 21).

The student determined the coordinates of the outline, identified the associated function $f(x)=$ $0.0247 \operatorname{sen}(35.7191 x+0.1717)$ and applied the formula for the arc length to approximate the length of the sheet.

Figure 21. Ribbed Sheet and its Sinusoidal Representation.
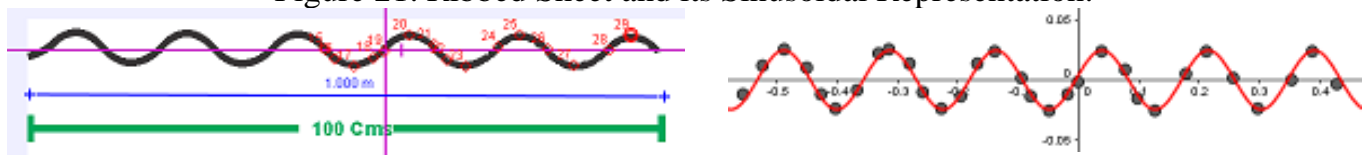

As part of the workshop, students were given a second problem: measuring the length of the arc of the curved section of an elevated bridge from the photograph shown in Figure 22. The photograph was taken as best possible using a cell phone camera. Students worked on obtaining data, for which they placed the coordinate axes and calculated the coordinates of the curved line for the bridge using Tracker. They fit the polynomial and approximated its length using GeoGebra.

Figure 22. Elevated Bridge and its Graphical and Analytical Representations.
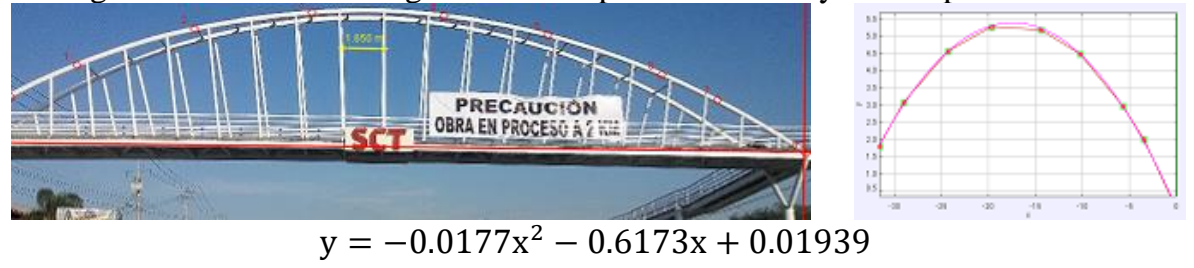

The second part of the activity was focused on calculating the magnitude of the missing part of the bridge in the photograph, so students fit the data to a parabola and approximated the magnitude assuming that the bridge is symmetrical. They did this by calculating the roots of equation $y=-0.0177 x^{2}-0.6173 x+0.01939$, to determine where the parabola crosses the $\mathrm{x}$-axis and they used the formula to calculate the arc length using GeoGebra.

\section{CONCLUSIONS}

The decision to analyze the selected problem situations was made once the students had worked on them. We observed a very important motivation for learning, relating and apply mathematics to problematic situations in their context, which we suggest should be made a part of school mathematics. 
Collaborative work was a strategy that benefitted and fostered the ability to make decisions and reach agreements. Discussion also arose, and this is an emerging object that serves to promote the learning and understanding of the various mathematics topics included in the examples.

The use of technology was also a great stimulant for students, since it facilitated the interpretation of data obtained from everyday situations. It also allowed the students to build their knowledge and reflect on the procedures used, as well as to identify the variables and parameters involved in real situations that are important for gaining understanding of the mathematical concept and its application in their everyday life environment.

These activities have been designed with the purpose of encouraging students to learn mathematics, to relate school mathematics to their everyday environment. Moreover, the actors involved in the teaching and learning of mathematics are present within an appropriate learning environment equipped with CIT where individual and group work are encouraged, where students take the initiative and are responsible for achieving meaningful learning. 


\section{REFERENCES}

Arrieta, J. \& Díaz, L. (2015). Una perspectiva de la modelación desde la Socioepistemología (A Socioepistemology perspective on modeling). RELIME, (18) 1: 19-48. DOI: 10.12802/relime.13.1811.

Bernárdez, A., Álvarez, J. S., Belmonte, M. L. (2021) La honestidad, la amistad y la autoestima: valores que promueven el clima relacional positivo. South Florida Journal of Development, v.2, n.1, p. 119-130. ISSN 26755459. DOI: 10.46932/sfjdv2n1-011.

Díaz Barriga, A. (2013). Guía para la elaboración de una secuencia didáctica (Guide for preparing a didactic sequence). Comunidad de Conocimiento UNAM. 1-15. Retrieved from http://www.setse.org.mx/ReformaEducativa/Rumbo\%20a\%20la\%20Primera\%20Evaluaci\%C3\%B3n/Factores\%2 0de\%20Evaluaci\%C3\%B3n/Pr\%C3\%A1ctica\%20Profesional/Gu\%C3\%ADa-secuenciasdidacticas Angel\%20D\%C3\%ADaz.pdf.

Duval, R. (2004). Los problemas fundamentales en el aprendizaje de las matemáticas y las formas superiores en el desarrollo cognitivo (Essential problems in the learning of mathematics and higher forms in cognitive development). Santiago de Cali, Colombia: Universidad del Valle, Instituto de Educación y Pedagogía, Grupo de Educación Matemática. ISBN: 958-670-329-0. 2004.

Ezquerra, A., Iturrioz, I. \& Díaz, M. (2011), Análisis experimental de magnitudes físicas a través de vídeos y su aplicación al aula (Experimental analysis of physical magnitudes through videos and its classroom application). Revista Eureka sobre Enseñanza y Divulgación de las Ciencias Universidad de Cádiz. APAC-Eureka. Available at http://hdl.handle.net/10498/14733. http://reuredc.uca.es. ISSN: 1697-011X. DOI: 10498/14733.

Freudenthal, H. (1981). Major problems of mathematics education. Educational Studies in Mathematics. 12: 133150. https://doi.org/10.1007/BF00305618.

Galilei, G. (1638). Dialogues Concerning Two New Sciences by Galileo Galilei. Translated from the Italian and Latin into English by Henry Crew and Alfonso de Salvio. With an Introduction by Antonio Favaro (New York: Macmillan, 1914). Retrieved from http://oll.libertyfund.org/titles/753.

Hit, F. \& Cortés, J. C. (2009). Planificación de actividades en un curso sobre la adquisición de competencias en la modelización matemática y uso de calculadora con posibilidades gráficas (Planning activities in a course on acquiring competence in mathematics modeling and using a graphing calculator). Revista digital Matemática, Educación e Internet. (10) 1: 2-30. Retrieved from www.cidse.itcr.ac.cr/revisamate/.

Hitt, F. \& González, A. (2015). Covariation between variables in a modelling process: The ACODESA (Collaborative Learning, Scientific Debate and Self-Reflection) method. Springer Science Business Media, 201219. Retrieved from https://papyrus.bib.umontreal.ca/xmlui/bitstream/handle/1866/18322/Hitt-GonzalezMartin2015-ESM-post.pdf?sequence $=1 \&$ is Allowed $=\mathrm{y}$.

Hockicko, P., Krišt'ák, L. \& Němec, M. (2015) Development of students' conceptual thinking by means of video analysis and interactive simulations at technical universities, European Journal of Engineering Education, (40) 2: 145-166, DOI: 10.1080/03043797.2014.941337.

Jofrey, J. (2010). Investigating the conservation mechanical energy using video analysis: four cases. Physics Education. (45) 1: 50-57 (2010). DOI 10.1088/0031-9120/1/005.

Pantoja, R. \& López, M. E. (2019). Ecuaciones paramétricas y la modelación de situaciones problema de la vida cotidiana con video (Parametric equations and modeling everyday life problem situations with video). Academia Journals Tepic 2019, (11) 1: 1070-1071. ISSN electrónico: 1946-5351.

Pantoja, R. (2020). La fotografía de hojas de árbol aplanadas como mediador para propiciar aprendizaje del cálculo de áreas (Photograph of flattened tree leaves as mediator to foster learning of area calculation). Brazilian Journal of Development, (6) 3: 9923-9940. DOI:10.34117/bjdv6n3-028. 
Pantoja, R., Ferreyra, R, \& Pantoja G., R. (2019). Secuencia didáctica para el cálculo de volumen por el método de sólidos de revolución: el caso de recipientes y sandía (Didactic sequence for calculating the volume of solids of revolution: the case of containers and watermelon) en Quiroz, S., Nuñez, E., Saboya, M., Soto, J. L. (Eds.), Investigaciones Teórico Prácticas sobre la Modelación Matemática en un Medio Tecnológico. Morelia, Mich., México: Editorial AMIUTEM. ISBN: 978-607-9860-30-1.

Pantoja, R., Guerrero, M. L., Nesterova, E., Ulloa, R. (2016). Modeling in problem situations of daily life. Journal of education and human development, (5) 1: 62-76. ISSN: 2334-2978 (electronic version). Doi: 10.15640/jehd.v5n1a1. ISSN: 2334-2978

Pantoja, R., Leal, O (2017). Sistema de prácticas de modelación con el Tracker y GeoGebra de cuerpos en movimiento para el aprendizaje del objeto derivada (Modeling practice system with Tracker and GeoGebra of bodies in movement for learning derived mathematical objects) en Martínez, C, y Romo, J. (Eds.), La enseñanza del cálculo: Diversas perspectivas sobre el diseño de actividades. Colima, México: Centro de Estudios Jurídicos y Sociales MISPAT, Universidad Autónoma de San Luis Potosí. ISBN: 978-607-8062-83-6.

Pantoja, R., Leal, O. \& Villapando, J. F. (2016). Sistema de prácticas de modelación matemática de objetos en movimiento (Practice systems for mathematical modeling of objects in movement). Revista Electrónica AMIUTEM, (IV) 2: 33-41. ISSN electrónico: 2395955X.

Pantoja, R., Leal, O., Pantoja, D. A. (2017), Situaciones problema de la vida cotidiana y su representación con funciones de la forma $\mathrm{f}(\mathrm{t})=(\mathrm{x}(\mathrm{t}), \mathrm{y}(\mathrm{t}))$ (Everyday life problem situations and their representation with functions of the form $\mathrm{f}(\mathrm{t})=(\mathrm{x}(\mathrm{t}), \mathrm{y}(\mathrm{t}))$. Acta Latinoamericana de Matemática Educativa, (30) 1: 1531-1542. ISSN electrónico: 2448-6469.

Pantoja, R., Nesterova, E. \& Ulloa, R. (2013). La modelación matemática en situaciones cotidianas con los software AVIMECA y MATHCAD (Mathematical modeling in everyday situations with AVIMECA and MATHCAD software). Revista GÓNDOLA, (8): 8-22. ISSN 2145-4981.

Pantoja, R., Ortega, M. I. \& Nesterova, E. (2017). Situaciones problema de la vida cotidiana, la matemática escolar y la modelación matemática: el caso del chorro de agua (Everyday life problem situations, school mathematics and mathematical modeling: the case of the water spout). Libro de actas. VIII Congreso Iberoamericano de Educación Matemática. Madrid, España: Federación Española de Sociedades de Profesores de Matemáticas ISBN: 978-8494572-23-4.

Pantoja, R., Sánchez, M. T. \& Ortega, M. I. (2017). Un acercamiento a la modelación matemática para el cálculo de áreas de objetos planos cotidianos con la fotografía, Tracker y GeoGebra (An approach to mathematical modeling for calculating the area of flat objects using prohography, Tracker and GeoGebra). Academia Journals 2017, (9) 6: 4904-4909. ISSN electrónico: 1946-5351.

Pantoja, R., Valdivia, S. M., Guerrero, M. L., \& Ulloa, R. (2018). La modelación matemática en situaciones problema de la vida cotidiana (Mathematical modeling in everyday life problem situations). Acta del XII Congreso Argentino de Educación Matemática, (XII) 1: 440-449. ISSN electrónico: 2618-3323.

Pollak H. (2007) Mathematical Modelling - a Conversation with Henry Pollak. In: Blum W., Galbraith P.L., Henn HW., Niss M. (eds) Modelling and Applications in Mathematics Education. New ICMI Study Series, (10): 109-120. SPRINGER, Boston, MA. https://doi.org/10.1007/978-0-387-29822-1_9

Steward, J. (2012). Cálculo de una Variable (Calculating variable). Trascendentes tempranas (Early transcendentals). Séptima edición. MEXICO, DF: CENCAGE LEARNING. ISBN 13: 9780840049360

Tobón, S., Pimienta, J., García, J. A. (2010). Secuencias didácticas: aprendizaje y evaluación de competencias (Didactic sequence: learning and assessing competencies). Pearson Educación: México. ISBN: 978-607-442-9091 . 